Rheumatoid arthritis

\section{Risk of lymphoma in patients with RA treated with anti-TNF $\alpha$ agents}

\section{J P Franklin, D P M Symmons, A J Silman}

\section{Does anti-TNF $\alpha$ treatment increase lymphoma risk independently of disease severity?}

T umour necrosis factor (TNF) $\alpha$, is a proinflammatory cytokine central to the pathogenesis of rheumatoid arthritis (RA). Drugs that block the action of this cytokine have been shown to be effective in reducing inflammation and slowing disease progression in patients with RA. ${ }^{2}$ TNF $\alpha$ also provides an essential immune function by promoting a cytotoxic response from T cells against $\mathrm{B}$ cell lymphomas. ${ }^{3}$ This raises a theoretical concern that agents blocking $T N F \alpha$ may contribute to an increased risk of such lymphomas, emphasising the need for long term safety surveillance of these drugs. These phenomena need to be considered against the background that the occurrence of lymphoma in patients with RA might be associated with disease activity or severity. If this were so, given the effectiveness of anti-TNF $\alpha$ agents, it is possible that their use may actually reduce lymphoma risk, or at least counteract any possible increase.

There is good evidence that the risk of lymphoma is related to RA severity. Baecklund and colleagues showed, using a nested case-control study of patients with RA with lymphoma, that inflammatory activity was strongly associated with the risk of developing lymphoma. This association persisted even after adjusting for differences in treatment exposure between groups. ${ }^{5}$ Overall, those patients classified as having "high inflammatory activity" were 25 times more likely to be diagnosed with lymphoma than those with "low inflammatory activity". Wolfe published similar data showing a relationship between a high erythrocyte sedimentation rate and the risk of lymphoma. ${ }^{6}$ Thus, any interpretation of the risk of lymphoma after anti-TNF treatment needs to take account of this important source of confounding.

\section{LYMPHOMA RISK IN ANTI-TNFa TREATED PATIENTS}

Several case reports of lymphoma developing after anti-TNF $\alpha$ treatment have been published. Thus, the Food and Drug Administration reported 26 cases after treatment with etanercept or infliximab, gathered as a part of standard pharmacovigilance practices. ${ }^{7}$ Unfortunately, no denominator data were available and it is not easy to determine directly if the rate of lymphoma in the treated patients was any higher than that of patients with RA in general.

\section{"The risk of lymphoma is related to RA severity, but is it greater when anti-TNF $\alpha$ agents are used"}

The first epidemiological study to examine that question used the National Data Bank for Rheumatic Diseases. ${ }^{8}$ This study followed up 18572 patients with RA, of whom, 8614 patients had ever been treated with a biological drug. Standardised incidence ratios (SIRs) were obtained by comparing the number of observed lymphomas with the number of expected cases, calculated by applying the rate of lymphomas in the general American population to the study cohort. The investigators found that in those patients exposed to anti-TNF $\alpha$ treatments, the risk of lymphoma was almost trebled. As there was no direct comparison between the two treatment groups, the complex relationship between biological drug treatment, severity, and lymphoma was not directly analysed in this study. Interestingly, given the previously reported increased lymphoma risk in RA cases overall, ${ }^{9-11}$ no statistically significant increase in the occurrence of lymphoma was detected in those non-biologically treated patients, including those exposed to methotrexate (MTX).

Against this background, the study by Geborek and colleagues, published in this issue, ${ }^{12}$ is welcome. It examines, for the first time, the question of whether use of anti-TNF $\alpha$ treatments increases the risk of lymphoma independently of disease severity. A national cohort of 757 Swedish patients exposed to etanercept or infliximab was followed up for an average of 2 years. Their risk of lymphoma was compared with that of a cohort of 800 patients with RA never exposed to any type of biological drug, who were followed up for an average of 5 years. SIRs for lymphoma in both groups were obtained using expected numbers calculated from the national rate. The authors showed that the risk of lymphoma in patients receiving biological drug treatments was about 10 times greater than that of the comparison cohort. More relevantly, a direct comparison showed that the hazard ratio for lymphoma was about 5 for anti-TNF $\alpha$ treated patients relative to the conventionally treated group. This increase persisted even after adjusting for differences in baseline Health Assessment Questionnaire (HAQ) scores, which were used as a marker of severity.

\section{METHODOLOGICAL ISSUES}

A number of methodological factors need to be considered when designing and analysing studies to examine this complex issue, most of which were acknowledged by Geborek and colleagues in their paper. Firstly, the possibility of confounding by indication-that is, those with the most severe and active disease receive the more powerful drugs, was unlikely to have been fully considered. Although Geborek and colleagues did make adjustments for the baseline HAQ score in their analyses, it would have been preferable to have seen results after more robust adjustments for the level and duration of disease activity.

\section{"Concern about lymphoma in anti- TNF treated patients may lead to earlier detection"}

Secondly, there is the problem of latency-specifically, a lymphoma diagnosed soon after starting biological drug treatment might have been present subclinically before that date. It is appropriate perhaps to apply an exclusion period, within which any newly diagnosed lymphoma is discounted, although the duration allowed is inevitably arbitrary. As an example, however, in the study by Geborek et al, ${ }^{12}$ allowing for a latency of 6 months would reduce the increased risk from 11.5 to 7.5, whereas a latency of 12 months would reduce this further to 2.5 .

Thirdly, there is the possibility of a reversed causality or protopathic bias. It is known that an apparent increase in arthritic symptoms in some subjects may actually be those of a developing lymphoma. ${ }^{13}$ If this was not recognised, the therapeutic response might be a change to a more aggressive treatment.

Fourthly, there may, in routine practice, be a surveillance bias or screening 
effect. Thus an enhanced concern about lymphoma in anti-TNF treated subjects may result in lymphoma being detected earlier than in patients with RA treated with conventional agents. As a result, any lymphomas would be detected in a shorter time period and as the patients were followed up for longer, such an effect would attenuate. It is thus important to ensure that the average period of follow up for each group (exposed and non-exposed) is approximately similar, whereas in the study by Geborek et al there was indeed a shorter follow up period in the anti-TNF group. ${ }^{12}$

Finally, as illustrated by the study it is difficult to obtain the large treated population sizes necessary to generate a sufficiently robust number of lymphoma cases to obtain effect estimates of risk with reasonable precision. Geborek et al only detected four cases of lymphoma and the failure to detect a significantly raised hazard ratio for the use of anti-TNF $\alpha$ may be explained by a type 2 error.

One additional finding of interest in this study was the failure to detect a raised incidence of lymphoma in their unexposed (conventionally treated) patients, despite detecting an increased risk of all-site cancers in this population. This is surprising as the results from several studies would suggest that a group of patients with RA severe enough to warrant treatment with MTX and other immunosuppressive drugs would be at an increased risk of lymphoma. ${ }^{9-11}{ }^{14-16}$ Conceivably, therefore, the comparison group was at an unusually low risk of lymphoma.

\section{CONCLUSION}

The study by Geborek and colleagues is welcome as it is the first direct attempt to investigate the relationship between disease severity, use of anti-TNF $\alpha$ agents, and risk of lymphoma in patients with RA. It is currently difficult to reach a robust conclusion on this question, which is clearly methodologically challenging. With increasing recruitment and follow up of such cohorts, a more definite answer should be available in the not too distant future.

Ann Rheum Dis 2005;64:657-658.

doi: 10.1136/ard.2005.035311

\section{Authors' affiliations}

J P Franklin, D P M Symmons, A J Silman,

ARC Epidemiology Unit, Manchester

University Medical School, Manchester M13

9PT, UK

Correspondence to: Professor A J Silman; a.silman@manchester.ac.uk

\section{REFERENCES}

1 Feldmann M, Maini RN. Discovery of TNF-alpha as a therapeutic target in rheumatoid arthritis: preclinical and clinical studies. Joint Bone Spine 2002;69:12-18.

2 Toussirot E, Wendling D. The use of TNF-alpha blocking agents in rheumatoid arthritis: an overview. Expert Opin Pharmacother 2004:5:581-94.

3 Lens SM, Tesselaar K, den Drijver BF, van Oers MH, van Lier RA. A dual role for both CD40ligand and TNF-alpha in controlling human B cell death. J Immunol 1996; 156:507-14.

4 Wallgren A, Festin R, Gidlof C, Dohlsten M, Kalland T, Totterman TH. Efficient killing of chronic B-lymphocytic leukemia cells by superantigen-directed T cells. Blood 1993:82:1230-8.
5 Baecklund E, Ekbom A, Sparen P, Feltelius N, Klareskog L. Disease activity and risk of lymphoma in patients with rheumatoid arthritis: nested case-control study. BMJ 1998:317:180-1.

6 Wolfe F. Inflammatory activity, but not methotrexate or prednisone use predicts nonHodgkin's lymphoma in rheumatoid arhtritis: a 25 year study of 1,767 RA patients [abstract]. Arthritis Rheum 1998;41(suppl 9): 188

7 Brown SL, Greene MH, Gershon SK, Edwards ET, Braun MM. Tumor necrosis factor antagonist therapy and lymphoma development: twenty-six cases reported to the Food and Drug Administration. Arthritis Rheum 2002;46:3151-8.

8 Wolfe F, Michaud K. Lymphoma in rheumatoid arthritis: the effect of methotrexate and anti-tumor necrosis factor therapy in 18,572 patients. Arthritis Rheum 2004;50:1740-51.

9 Asten P, Barrett J, Symmons D. Risk of developing certain malignancies is related to duration of immunosuppressive drug exposure in patients with rheumatic diseases. J Rheumatol 1999;26:1705-14.

10 Prior P, Symmons DP, Hawkins CF, Scott DL, Brown R. Cancer morbidity in rheumatoid arthritis. Ann Rheum Dis 1984;43:128-31.

11 Silman AJ, Petrie J, Hazleman B, Evans SJ. Lymphoproliferative cancer and other malignancy in patients with rheumatoid arthritis treated with azathioprine: a 20 year follow up study. Ann Rheum Dis 1988:47:988-92.

12 Geborek P, Bladström A, Turesson C, Gulfe A, Petersson I, Saxne T, et al. Tumour necrosis factor blockers do not increase overall tumour risk in patients with rheumatoid arthritis, but may be associated with an increased risk of lymphomas. Ann Rheum Dis 2005;64:699-703.

13 von Kempis J, Kohler G, Herbst EW, Peter HH. Intravascular lymphoma presenting as symmetric polyarthritis. Arthritis Rheum 1998;41:1126-30.

14 Baltus JA, Boersma JW, Hartman AP, Vandenbroucke JP. The occurrence of malignancies in patients with rheumatoid arthritis treated with cyclophosphamide: a controlled retrospective follow-up. Ann Rheum Dis 1983;42:368-73.

15 Isomaki HA, Hakulinen T, Joutsenlahti U. Excess risk of lymphomas, leukemia and myeloma in patients with rheumatoid arthritis. J Chronic Dis 1978;31:691-6.

16 Kinlen $\mathrm{L}$. Incidence of cancer in rheumatoid arthritis and other disorders after immunosuppressive treatment. Am J Med 1985;78:44-9. 